\title{
Analisa Struktur Dependensi Variabe Pembentukan Asuransi Pertanian Berbasis Indeks Cuaca dengan Multivariat Copula dan Vine Copula
}

\author{
Agus Sofian Eka Hidayath \\ Universitas Presiden \\ e-mail: agus.eka@president.ac.id
}

\begin{abstract}
The purpose of this study is to analyze the structure of the dependency on variables for calculation of insurance based on weather indices such as crop prices, yields, and rainfall. The object of research observation was secondary data on the sub-district of Dlingo Bantul District. In analyzing the dependency of variables that can be used in agricultural insurance calculations, it can be seen that both using multivariate copula and vine copula have the same results. A multivariate copula that directly looks at dependency relationships between three variables. Whereas copula vine can see the size values of the variable pair dependency for each edge in the copula vine tree. In more detail the best dependency for the grain price and rainfall variable is Copula Joe with the parameter $\theta=1.76$. correlation $\tau=0.3$. The best dependency between rainfall and yield is Frank Copula with parameters $\theta=4.98$ and correlation $\tau=0.46$. The best dependency between rainfall and yield is Frank copula with parameters $\theta=2.42$ and correlation $\tau=0.25$.
\end{abstract}

Key words: Agricultural Insurance, Weather Index, Dependencies, Vine Copula, Multivariate Copula

\begin{abstract}
Abstrak
Tujuan dari penelitian ini adalah untuk menganalisa struktur depedensi pada variable-variabel untuk perhitungan asuransi pertaian berbasis indeks cuaca seperti harga panen, hasil panen, dan curah hujan. Objek observasi penelitian adalah data-data skunder pada distik di Kecamatn Dlingo Bantul. Dalam menganalisa depedensi variable-variabel yang dapat digunakan dalam perhitunagn asuransi pertanian, dapat dilihat bahwa baik menggunakan multivariate copula dan vine copula memiliki hasil yang sama. Copula multivariate yang secara langsung melihat hubungan depedensi antara tiga variable. Sedangkan copula vine dapat melihat nilai-nilai ukuran depedensi anatar pasangan variable untuk setiap edge pada pohon copula vine. Secara lebih mendetail dependensi terbaik untuk variabel harga gabah dan curah hujan adalah Copula Joe dengan parameter $\theta=1.76$. korelasi $\tau=0.3$. Dependensi terbaik antara curah hujan dan hasil panen adalah Copula Frank dengan parameter $\theta=4.98$ dan korelasi $\tau=0.46$. Dependensi terbaik antara curah hujan dan hasil panen adalah copula Frank dengan parameter $\theta=2.42$ dan korelasi $\tau=0.25$.
\end{abstract}

Kata kunci: Asuransi Pertanian,, Indeks Cuaca, Dependensi, Vine Copula, Multivariat Copula 


\section{PENDAHULUAN}

Indonesia merupakan negara agraris yang memiliki potensi besar di sektor pertanian. Saat ini sector pertanian di Indonesia memegang peranan penting pada ekonomi nasional Indonesia [1]. Hal ini ditunjukkan dengan banyaknya masyarakat yang menggantungkan usahanya pada sektor pertanian, seperti menjadi petani padi. Akan tetapi usaha di sektor pertanian masih dihadapkan pada resiko ketidakpastian yang cukup tinggi. Hal ini disebabkan karena kegagalan panen yang diakibatkan oleh perubahan iklim seperti banjir, kekeringan, dan serangan hama. Untuk mengurangi kerugian resiko pertanian, perlu adanya asuransi yang melindungi usaha petani.

Pada umumnya terdapat dua metode yang banyak digunakan di beberapa negara berkembang sebagai acuan dalam mendesain kontrak asuransi pertanian yaitu kontrak asuransi berbasis hasil pertanian atau actual production history (APH), dan kontrak asuransi berbasis pendapatan atau revenue insurance contract. Dalam kajian penelitian lainnya terdapat pula asuransi yang menggunakan indeks cuaca dalam memberikan memberikan jaminan kerugian saat terjadi kemarau (drought).

Asuransi Usaha Tani Padi (AUTP) merupakan solusi yang ditawarkan oleh pemerintah untuk melindungi masyarakat dari kerugian akibat resiko pertanian, dinilai terlalu mahal dan memiliki persyaratan pertanggungan yang cukup komplek. Hal ini berdampak pada rendahnya minat petani untuk membeli asuransi pertanian ini dimana data AUTP untuk Pulau Jawa, Bali, dan Nusa Tenggara baru mencapai 232.255 hektar dari target 1 juta hektar [2]. AUTP yang diterapkan di Indonesia tergolong pada asuransi pertanian tradisional yang sudah mulai ditinggalkan sebab, pada negara maju dan berkembang seperti Australia, Cina, India, Iran sudah bergerak kearah asuransi pertanian berbasis indeks cuaca [3][4]. Asuransi berbasis indeks cuaca merupakan alternatif yang dapat digunakan oleh perusahaan asuransi sebagai pengganti model asuransi pertanian yang masih tradisional [5]. Penelitian [6] menujukkan bahwa asuransi pertanian berbasis indeks cuaca dapat memberikan biaya yang lebih murah dibandingkan dengan asuransi pertanian yang lebih tradisional.

Adanya keterkaitan erat (dependency) antara indeks cuaca (weather index) dengan hasil pertanian (yield) merupakan landasan pembentukan asuransi berbasis indeks cuaca [7]. Perubahan cuaca, terutama, sangat berdampak pada sektor pertanian. Sehingga, bentuk kontrak asuransi pertanian dengan berdasarkan indeks cuaca menjadi lebih reliable dan beresuaian dengan kebutuhan petani. Untuk membangun produk asuransi ini, diperlukan kajian tentang dependensi hasil pertanain dengan indeks cuaca yang ada seperti curah hujan, intensitas matahari, kecepatan angin, dan kelembapan [7]. Saat ini, asuransi berbasis indeks cuaca, telah memberikan opsi pendekatan yang lebih baik untuk menanggulangi resiko pada usaha pertanian tertuama pada lahan pertanian yang rawan akan bencana kekeringan [3].

Dalam bidang statistika, suatu dependensi dari multivariable dapat dilihat dengan menggunakan teknik copula. Pada konteks asuransi pertanian penggunaan copula menjadi sangat reliable karena struktur dependensi yang digambarkan menyesuaikan dengan perubahan waktu serta mampu memberikan nilai perbandingan yang lebih baik pada indeks cuaca dan resiko penuruan hasil pertanian [8]. Pada umumnya dependensi suatu multivariable dapat diukur menggunakan struktur korelasi linear [9] dan multivariat copula [10]. Teknik multivariat copula dapat juga digantikan dengan Copula Vine yang memandang multivariat copula sebagai pasangan bivariat copula. Sehingga penggambaran struktur dependensi dapat dilakukan secara lebih akurat dibandingkan menggunakan multivariat copula [9][10].

\section{METODE PENELITIAN}

\section{Teorema Sklar}

Diberikan $\mathrm{F}$ fungsi distribusi gabungan berdimensi $\mathrm{d}$, dengan fungi marginal $F_{1}, F_{2}, \ldots, F_{d}$. Terdapat copula $C$ dengan dimensi $d$ sehingga untuk setiap $\mathrm{x}_{1}, \mathrm{x}_{2}, \ldots, \mathrm{x}_{\mathrm{d}} \in \mathbb{R}$ berlaku,

$$
\mathrm{F}\left(\mathrm{x}_{1}, \mathrm{x}_{2}, \ldots, \mathrm{x}_{\mathrm{d}}\right)=\mathrm{C}\left(\mathrm{F}_{1}\left(\mathrm{x}_{1}\right), \ldots, \mathrm{F}_{\mathrm{d}}\left(\mathrm{x}_{\mathrm{d}}\right)\right) \text {. }
$$

Jika $\mathrm{F}_{1}, \ldots, \mathrm{F}_{\mathrm{d}}$ kontinu maka $\mathrm{C}$ tunggal. Sebaliknya jika $\mathrm{C}$ merupakan copula berdimensi d dan $\mathrm{F}_{1}, \ldots, \mathrm{F}_{\mathrm{d}}$ merupakan fungsi 
distribusi marginal, maka fungsi $\mathrm{F}\left(\mathrm{x}_{1}, \mathrm{x}_{2}, \ldots, \mathrm{x}_{\mathrm{n}}\right)=\mathrm{C}\left(\mathrm{F}_{1}\left(\mathrm{x}_{1}\right), \ldots, \mathrm{F}_{\mathrm{d}}\left(\mathrm{x}_{\mathrm{d}}\right)\right)$ adalah fungsi distrbusi gabungan berdimensi d.

\section{Fungsi Densitas Probabilitas Copula}

Diberikan variabel acak berdimensi $\mathrm{d}, \mathbf{X}=$ $\left(\mathrm{X}_{1}, \mathrm{X}_{2}, \ldots, \mathrm{X}_{\mathrm{d}}\right)$, dengan fungsi gabungan densitas $\mathrm{f}\left(\mathrm{x}_{1}, \ldots, \mathrm{x}_{2}\right)$. Fungsi densitas gabungan dapat secara rekrusive difaktorkan menggunakan denistas bersyarat:

$$
\begin{aligned}
& \mathrm{f}\left(\mathrm{x}_{1}, \ldots, \mathrm{x}_{\mathrm{d}}\right)=\mathrm{f}_{1}\left(\mathrm{x}_{1}\right) \cdot \mathrm{f}_{2 \mid 1}\left(\mathrm{x}_{2} \mid \mathrm{x}_{1}\right) \cdot \\
& =\mathrm{f}_{3 \mid 2,1}\left(\mathrm{x}_{3} \mid \mathrm{x}_{1}, \mathrm{x}_{2}\right) \cdot \ldots \cdot \mathrm{f}_{\mathrm{d} \mid 1:(\mathrm{d}-1)}\left(\mathrm{x}_{\mathrm{d}} \mid \mathrm{x}_{1}, \ldots, \mathrm{x}_{\mathrm{d}}\right) \\
& =\prod_{\mathrm{t}=2}^{\mathrm{d}} \mathrm{f}_{\mathrm{t} \mid 1:(\mathrm{t}-1)}\left(\mathrm{x}_{\mathrm{t}} \mid \mathrm{x}_{1}, \ldots, \mathrm{x}_{\mathrm{t}-1}\right) \cdot \mathrm{f}_{1}\left(\mathrm{x}_{1}\right) .
\end{aligned}
$$

Dengan memanfaatkan pengetahuan tentang fungsi densitas gabungan dan densitas bersyarat maka untuk $\mathbf{v}=\left(v_{1}, \ldots, v_{d}\right)$, dan $\mathbf{v}_{-\mathbf{j}}=\left(v_{1}, \ldots, v_{j-1}, v_{j+1}, \ldots, v_{d}\right) \quad j=1, \ldots, d$ denistas bersyarat dapat dinyatakan dalam bentuk fungsi copula sebagai berikut

$$
f(x \mid v)=c_{x v_{j} \mid v_{-j}}\left(F\left(x \mid v_{-j}\right), F\left(v_{j} \mid v_{-j}\right) \cdot f\left(x \mid v_{-j .} \quad(3\right.\right.
$$

\section{Fungsi Distribusi Bersyarat Copula}

Berdasarkan persamaan (3) cdf bersyarat dalam copula dapat ditunjukkan dalam [11]

$$
F(x \mid v)=\frac{\partial C_{x, v_{j} \mid v_{-j}}\left(F\left(x \mid v_{-j}\right), F\left(v_{j} \mid v_{-j}\right)\right)}{\partial F\left(v_{j} \mid v_{-j}\right)} .
$$

\section{Keluarga Copula}

\section{a) Copula Archimedean}

Copula C dengan dimensi $\mathrm{d} \geq 2$ disebut Archimedean jika terdapat pembangkit (generator) $\varphi$, sehingga untuk setiap $\mathrm{u}=$ $\left(\mathrm{u}_{1}, \ldots, \mathrm{u}_{\mathrm{d}}\right) \in \mathrm{I}^{\mathrm{d}}$ dipunyai

$$
\mathrm{C}(\mathrm{u})=\varphi^{-1}\left(\varphi\left(\mathrm{u}_{1}\right)+\cdots+\varphi\left(\mathrm{u}_{\mathrm{d}}\right)\right)
$$

dengan $\varphi(0)=\infty$ dan $\varphi(1)=0$. Fungsi pembangkit (generator) ini mendefinisikan spesifikasi dari copula Archimedean. Jika dipunya $\varphi(0)$ berhingga (finite), maka copula Archimedean dibangkitkan dengan menggunakan pseudo inverse dari $\varphi$ yaitu:

$$
\begin{aligned}
& \varphi^{[-1]}(\mathrm{t}) \\
& =\left\{\begin{array}{cc}
\varphi^{-1}(\mathrm{t}) & , 0 \leq \mathrm{t} \leq \varphi(0) \\
0 & , \varphi(0) \leq \mathrm{t} \leq \infty
\end{array}\right.
\end{aligned}
$$

Adapun keluarga copula Archimedean terdiri atas copula Clayton, copula Gumbel, copula Fank, dan copula Joe. Berikut dijabarkan nilai- nilai untuk generator, Kendal, dan parameter dari tiap keluarga copula Archimedean.

Tabel 1. Copula Archimedean

\begin{tabular}{|c|c|c|}
\hline $\begin{array}{c}\text { Nama } \\
\text { Copula }\end{array}$ & Generator $\varphi_{\theta}(t)$ & Parameter \\
\hline Clayton & $\frac{1}{\theta}\left(t^{-\theta}-1\right)$ & $\theta>0$ \\
\hline Gumbel & $(-\ln (t))^{\theta}$ & $\theta \geq 1$ \\
\hline Frank & $-\ln \left(\frac{e^{-\theta t}-1}{e^{-\theta}-1}\right)$ & $\theta \in \mathbb{R}$ \\
\hline Joe & $-\ln (1$ & $\theta \geq 1$ \\
\hline
\end{tabular}

Selanjutnya fungsi distribusi gabungan copula Clayton adalah

$$
C\left(u_{1}, \ldots, u_{d}\right)=\left[\left(\sum_{i=1}^{d} u_{i}^{-\theta}\right)-d+1\right]^{-\frac{1}{\theta}}
$$

dengan bivariat copulanya memiliki bentuk

$$
C\left(u_{1}, u_{2}\right)=\left(u_{1}^{-\theta}+u_{2}^{-\theta}-1\right)^{-\frac{1}{\theta}} \text {. }
$$

Fungsi distribusi gabungan untuk copula Gumbel adalah

$$
C\left(u_{1}, \ldots, u_{d}\right)=\exp \left\{-\left[\sum_{i=1}^{d}\left(-\ln u_{i}\right)^{\theta}\right]^{\frac{1}{\theta}}\right\}
$$

dengan bivariat copula

$$
\begin{aligned}
C\left(u_{1}, u_{2}\right)=\exp & \left\{-\left[\left(-\ln u_{1}\right)^{\theta}\right.\right. \\
+ & \left.\left.\left(-\ln u_{2}\right)^{\theta}\right]^{\frac{1}{\theta}}\right\} .
\end{aligned}
$$

Fungsi distribusi gabungan copula Frank adalah

$$
\begin{aligned}
C\left(u_{1}, \ldots, u_{d} ; \theta\right) & =-\frac{1}{\theta} \ln [1 \\
& \left.+\frac{\prod_{i=1}^{d}\left[e\left(-\theta u_{i}\right)-1\right]}{\left(e^{-\theta}-1\right)}\right]
\end{aligned}
$$

dengan bivariat copula

$$
\begin{aligned}
C\left(u_{1}, u_{2}\right)=- & \frac{1}{\theta} \ln (1 \\
& \left.+\frac{\left(e^{-\theta u_{1}}-1\right)\left(e^{-\theta u_{2}}-1\right)}{\left(e^{-\theta}-1\right)}\right)
\end{aligned}
$$

Fungsi distribusi copula Joe adalah 


$$
\begin{aligned}
C\left(u_{1}, \ldots, u_{d} ; \theta\right) & =1 \\
& -\left(\left(\sum_{i=1}^{d}\left(1-u_{i}\right)^{\theta}\right)\right. \\
& \left.-\left(\prod_{i=1}^{d}\left(1-u_{i}\right)^{\theta}\right)\right)^{\frac{1}{\theta}}
\end{aligned}
$$

dengan

$$
\begin{array}{r}
C\left(u_{1}, u_{2}\right)=-1-\left[\left(1-u_{1}\right)^{\theta}+\left(1-u_{2}\right)^{\theta}\right. \\
\left.-\left(1-u_{1}\right)^{\theta}\left(1-u_{2}\right)^{\theta}\right]^{\frac{1}{\theta}}
\end{array}
$$

\section{b) Copula Elliptical}

Copula Eliptical didefinisikan sebagai copula yang berkaitan dengn distribusi Elliptical F. Adapun keluarga dari Elliptical Copula diantaranya Copula Students' $t$ dan Copula Gaussian. Copula Elliptical merupakan bentuk analitik dari teorema Sklar dari fungsi distribusi F. Secara umum bentuk copula Elliptical adalah sebagai berikut

$$
\mathrm{C}\left(\mathrm{u}_{1}, \ldots, \mathrm{u}_{\mathrm{d}}\right)=\mathrm{F}\left(\mathrm{F}_{1}^{-1}\left(\mathrm{u}_{1}\right), \ldots, \mathrm{F}_{\mathrm{d}}^{-1}\left(\mathrm{u}_{\mathrm{d}}\right)\right)
$$

$\left(u_{1}, \ldots, u_{d}\right) \in[0,1]^{d}, F_{n}^{-1}, n=1, \ldots, d$ adalah fungsi inverse univariat.

Copula Students't, $\mathrm{C}_{\mathrm{t}}(\mathrm{u} ; \mathrm{P}, \mathrm{v})$, adalah copula dari $\mathrm{X} \sim \mathrm{t}_{\mathrm{d}}(0, \mathrm{P}, \mathrm{v})$ dimana $\mathrm{P}$ merupakan matrik korelasi. Copula $t$ berdimensi $d$ memiliki bentuk analytic

$$
\mathrm{C}_{\mathrm{t}}(\mathrm{u} ; \mathrm{P}, \mathrm{v})=\mathrm{t}_{\mathrm{P}, \mathrm{v}}\left(\mathrm{t}_{\mathrm{v}}^{-1}\left(\mathrm{u}_{1}\right), \ldots, \mathrm{t}_{\mathrm{v}}^{-1}\left(\mathrm{u}_{\mathrm{d}}\right)\right)
$$

dimana $\left(u_{1}, \ldots, u_{d}\right) \in[0,1]^{d}, t_{P, v}$, adalah fungsi distribusi gabungan dari variabel random $\mathrm{X}$ dan $\mathrm{t}_{\mathrm{v}}^{-1}$ adalah fungsi inverse dari distribusi marginal standar dari distribusi $t$ dengan derajat kebebasan v

Copula Gaussian atau copula Normal, $\mathrm{C}_{\mathrm{G}}(\mathrm{u} ; \mathcal{R})$, adalah copula dari $\mathrm{X} \sim \mathrm{N}_{\mathrm{d}}(0, \mathcal{R})$ dimana $\mathcal{R}$ merupakan matrik korelasi. Bentuk umum dari copula Gaussian adalah

$$
\mathrm{C}_{\mathrm{G}}(\mathrm{u} ; \mathcal{R})=\Phi_{\mathcal{R}}\left(\Phi^{-1}\left(\mathrm{u}_{1}\right), \ldots, \Phi^{-1}\left(\mathrm{u}_{\mathrm{d}}\right)\right)
$$

dengan $\left(u_{1}, \ldots, u_{d}\right) \in[0,1]^{\mathrm{d}}, \Phi_{\mathcal{R}}$ merupakan fungsi distribusi gabungan dari variabel random $\mathrm{X}=\left(\mathrm{X}_{1}, \ldots, \mathrm{X}_{\mathrm{d}}\right)$ dan $\Phi^{-1}$ adalah invers dari distribusi marginal normal standar

\section{5. h-Fungsi Bivariat Copula}

Untuk mengilustrasikan nilai fungsi $\mathrm{h}$ dan $\mathrm{h}^{-1}$ dalam bivariat copula akan diberikan contoh pada keluarga copula Elliptical dan copula Archimedean.
Diketahui nilai CDF dari copula Gauss adalah

$$
\begin{aligned}
& \mathrm{C}_{\mathcal{R}}^{\text {Gauss }}\left(\mathrm{u}_{1}, \mathrm{u}_{2}\right)=\Phi_{\mathcal{R}}\left(\Phi^{-1}\left(\mathrm{u}_{1}\right), \Phi^{-1}\left(\mathrm{u}_{2}\right)\right) \\
& =\int_{-\infty}^{\Phi^{-1}\left(\mathrm{u}_{1}\right)} \int_{-\infty}^{\Phi^{-1}\left(\mathrm{u}_{2}\right)} \phi_{2}\left(\mathrm{x}_{1}, \mathrm{x}_{2}\right) \mathrm{dx}_{1} \mathrm{dx}_{2}, \\
& \text { dimana } \mathcal{R}:=\left(\begin{array}{ll}
1 & \rho \\
\rho & 1
\end{array}\right), \quad \text { dan } \quad \phi_{2}\left(\mathrm{x}_{1} \cdot \mathrm{x}_{2}\right)= \\
& \frac{1}{2 \pi\left(1-\mathcal{R}^{2}\right)^{\frac{1}{2}}} \cdot \mathrm{e}^{-\frac{\mathrm{x}_{1}^{2}-2 \rho_{12}^{2} \mathrm{x}_{1} \mathrm{x}_{2}+\mathrm{x}_{2}^{2}}{2\left(1-\rho_{12}^{2}\right)}} \text { merupakan }
\end{aligned}
$$

densitas bivariat Gauss dengan mean 0 , variansi 1 dan korelasi parameter $\rho_{12}$, dan $\Phi_{\mathcal{R}}$ menotasikan CDF terkait. Misalkan $\mathrm{q}_{1}:=$ $\Phi^{-1}\left(\mathrm{u}_{1}\right)$ dan $\mathrm{q}_{2}:=\Phi^{-1}\left(\mathrm{u}_{2}\right)$, maka h-fungsi dari copula Gauss adalah [12]

$$
h\left(u_{1}, u_{2}\right)=\Phi\left(\frac{\left(q_{1}-\rho_{12} q_{2}\right)}{\left(1-\rho_{12}^{2}\right)^{\frac{1}{2}}}\right) .
$$

Berdasarkan fungsi $h$ diperoleh fungsi $h$ inverse, $\mathrm{h}^{-1}$, sebagai berikut

$$
\begin{aligned}
\mathrm{h}^{-1}\left(\mathrm{u}_{1}, \mathrm{u}_{2}\right)= & \Phi\left(\Phi^{-1}\left(\mathrm{u}_{1}\right) \cdot\left(1-\rho_{12}^{2}\right)^{\frac{1}{2}}\right. \\
& \left.+\rho_{12}^{2} \Phi^{-1}\left(\mathrm{u}_{2}\right)\right)
\end{aligned}
$$

\section{Uji Independent dan Seleksi Copula}

Uji independent pada bivariat copula dapat dilakukan berdasarkan nilai Kendall's tau dimana

Statistic $:=\mathrm{T}=\sqrt{\frac{9 N(N-1)}{2(2 N+5)}} \times|\hat{\imath}|$

Dimana $N$ merupakan jumlah observasi data, dan $\hat{\tau}$ merupakan nilai empirical Kendall's tau dari pasangan vector, misal $u_{1}$ dan $u_{2}$.

Nilai minimum AIC digunakan pada estimasi distribusi terbaik, sedangkan nilai minimum BIC digunakan untuk estimasi copula terbaik. Perhitungan nilai AIC dan BIC untuk bivariat keluarga copula $c$ dimana untuk observasi $u_{i, j}, i=1, \ldots, N, j=1,2$ dan

AIC $=-2($ Log likelihood $)+2 k$

$$
:=-2 \sum_{i=1}^{N} \ln \left[c\left(u_{i, 1}, u_{i, 2}\right) \mid \theta\right]+2 k
$$

Formula dari Bayesian Model Evaluation Criterion (BIC) sama dengan formula AIC, tetapi dengan penalty yang berbeda untuk jumlah parameter.

$\mathrm{BIC}=-2(\log$ likelihood $)+\ln (\mathrm{N}) k$

$$
:=-2 \sum_{i=1}^{N} \ln \left[c\left(u_{i, 1}, u_{i, 2}\right) \mid \theta\right]+\ln (\mathrm{N}) k
$$




\section{Estimasi Parameter dengan Maksimum Likelihood}

Dipunyai M vektor variabel random berdistribusi multivariate berdimensi $\mathrm{d}$ yang iid $, \hat{x}_{1}, \ldots, \hat{x}_{d}, \hat{x}_{i}=\left\{\hat{x}_{i, 1}, \hat{x}_{i, 2}, \ldots, \hat{x}_{i, d}\right), i \in$ $\{1, \ldots, d\}$. Distribusi marginal $\mathrm{F}_{1}, \ldots, \mathrm{F}_{\mathrm{d}}$ dengan parameter $\beta_{1}, \ldots, \beta_{\mathrm{d}}$ dan parameter copula $\theta$, densitas distribusi multivariat $\mathrm{f}$, dapat dituliskan

$$
f\left(x_{1}, \ldots, x_{d}\right)=c\left(F_{1}\left(x_{1} ; \beta_{1}\right), \ldots, F_{d}\left(x_{d} ; \beta_{d}\right) ; \theta\right)
$$

Selanjutnya, parameter copula tersebut dapat diestimasi dari data dengan menggunakan MLE sebagai berikut

$\hat{\theta}$

$$
=\arg _{\alpha_{1}, \ldots x_{n}, \theta} \sum_{j=1}^{\mathrm{d}} \ln \left(c\left(\mathrm{~F}_{1}\left(\hat{\mathrm{x}}_{\mathrm{j}, 1} ; \beta_{1}\right), \ldots, \mathrm{F}_{\mathrm{n}}\left(\hat{\mathrm{x}}_{\mathrm{j}, \mathrm{n}} ; \beta_{\mathrm{n}}\right) ; \theta\right) \prod_{\mathrm{i}=1}^{\mathrm{n}} \mathrm{f}_{\mathrm{i}}\left(\hat{\mathrm{x}}_{\mathrm{j}, 1} ; \beta_{\mathrm{i}}\right)\right.
$$

\section{Copula Vine dan Strutktur Vine}

Untuk memudahkan pembentukan struktur dari multivariat copula, diperkenalkan struktur grafik yang menggambarkan PCC dengan rangkaian jaringan pohon copula atau yang dikenal dengan vine tree. $\mathcal{V}=$ $\left(\mathrm{T}_{1}, \ldots, \mathrm{T}_{\mathrm{d}-1}\right)$ merupakan rangkaian pohon $\mathrm{R}$ vine dengan dimensi d jika [7][13]

1. $\mathrm{T}_{1}$ merupakan pohon dengan nodes $\mathrm{N}_{1}=$ $\{1, \ldots, d\}$ dan himpunan dari edges $E_{1}$.

2. Untuk $\mathrm{j} \geq 2, \mathrm{~T}_{\mathrm{j}}$ adalah pohon dengan node $N_{j}=E_{j-1}$ dan edges $E_{j}$

3. Untuk $j=2, \ldots, d-1$ dan $\{a, b\} \in E_{j}$ harus memenuhi $|a \cap b|=1$

Lebih khusus rangakain pohon $\mathrm{R}$-vine $\mathcal{V}=$ $\left(\mathrm{T}_{1}, \ldots, \mathrm{T}_{\mathrm{d}-1}\right)$ disebut Rangakaian pohon Dvine jika setiap node $n \in N_{j}$ dipunyai

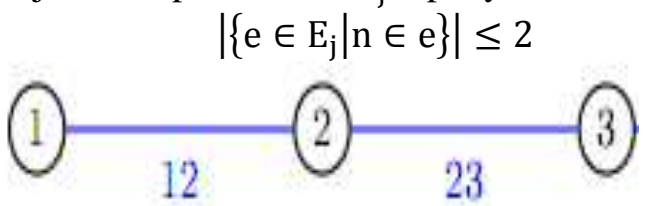

Gambar 1. Sturktur Copula D-Vine berdimensi $(d=3)$

\section{Sampling Data Copula pada Struktur $d=3$}

Apabila diberikan suatu variabel random $U_{1}, U_{2}, U_{3} \in[0,1]$, dengan memperhatikan algoritma pembentukan data sampel pada Copula Vine, maka menurut Czado and Stober sebagaimana yang dikutip dalam [12], untuk struktur Copula Vine $(d=3)$ dapat dibentuk sampel $W_{1}, W_{2}$, dan $W_{3}$. Nilai $W_{3}=U_{3}$, sedangkan untuk $W_{2}$ dipunyai

$$
F\left(w_{2} \mid w_{3}\right)=\frac{\partial C_{1,2}\left(w_{2}, w_{3}\right)}{\partial w_{3}}=h\left(w_{2} ; w_{3}, \theta_{1,2}\right) \text {, }
$$

sehingga,

$$
W_{2}=F_{2 \mid 1}^{-1}\left(U_{2} \mid W_{1}\right)=h^{-1}\left(U_{2} ; W_{1}, \theta_{1,2}\right) \text {. }
$$

Sedangkan untuk $W_{3}$ dipunyai,

$\mathrm{d}^{F} F\left(w_{3} \mid w_{1}, w_{2}\right)=\frac{\partial C_{3,1 \mid 2}\left(F\left(w_{3} \mid w_{2}\right),\left(F\left(w_{1} \mid w_{2}\right)\right)\right.}{\partial F\left(w_{1} \mid w_{2}\right)}$

$\prod_{i=1}=f_{h}\left(F_{i}\left(\beta_{\beta}\right) \mid w_{2} ; F\left(w_{1} \mid w_{2}\right), \theta_{1,3 \mid 2}\right)$

Sehingga diperoleh,

$$
\begin{aligned}
& W_{3}=F_{32,1}^{-1}\left(U_{3} \mid W_{1}, W_{2}\right) \\
& =h^{-1}\left(h^{-1}\left(u_{3} ;\left(h\left(w_{2} ; w_{1}, \theta_{1,2}\right), \theta_{1,3 \mid 2}\right) ; w_{1}, \theta_{1,3}\right) .\right.
\end{aligned}
$$

\section{HASIL dan PEMBAHASAN}

\section{Interpretasi Data}

Jenis data yang digunakan dapat dikelompokkan menjadi dua jenis data yaitu data sekunder dan data simulasi. Data sekunder yang digunakan adalah data curah hujan kumulatif (November-Februari dan Maret-Juni) di Kecamatan Dlingo, Data hasil panen dan harga gabah panen diperoleh dari mantri tani di Balai Penyuluhan Pertanian Kecamatan Dlingo, Kabupaten Bantul tahun 1999-2018.

Selanjutnya, dilakukan uji distribusi untuk data dari variabel harga gabah $(P)$, hasil panen $(Y)$, dan curah hujan kumulatif $(C)$. Hasil uji korelasi Kendall Tau pasangan variabel untuk korelasi Kendall Tau dari variabel hasil panen dan indek standar curah hujan, dan hasil panen dan harga gabah berturut-turut adalah $0.0008459<0.05$ dan $0.01758<0.05$. Hal ini mengindikasikan hubungan antara variabel hasil panen dan harga gabah serta hasil panen dan curah hujan tidak lemah. bahwa hubungan antara luas hasil panen dan indek standar curah hujan lebih kuat dari pada luas hasil panen dan indek harga gabah, dimana kuat hubungan anatara hasil panan dan harga gabah adalah 0.3071626 atau 30.72\%, sedangkan kuatnya hubungan hasil panen dan curah hujan sebesar 0.4574713 atau $45.09 \%$.

Berdasarkan nilai AIC pada tiap-tiap distribusi, diperoleh bahwa nilai AIC untuk 
semua variabel lebih rendah pada distribusi Lognormal dari pada Weibull.

Tabel 2. Uji Statistik dan Godness of Fit pada Variabel P, Y, dan C

\begin{tabular}{|c|c|c|c|c|}
\hline $\begin{array}{l}\text { Vari } \\
\text { abel }\end{array}$ & $\begin{array}{l}\text { Distrib } \\
\text { usi }\end{array}$ & Parameter & AIC & BIC \\
\hline \multirow[t]{2}{*}{$\mathrm{P}$} & $\begin{array}{l}\text { Lognor } \\
\text { mal }\end{array}$ & $\begin{array}{l}\mu \\
=8.184343 \\
\sigma \\
=0.084240\end{array}$ & $\begin{array}{l}431.7 \\
525\end{array}$ & $\begin{array}{l}434.5 \\
549\end{array}$ \\
\hline & Weibull & $\begin{array}{l}\mathrm{k} \\
=12.97443 \\
\lambda \\
=3734.835\end{array}$ & $\begin{array}{l}433.3 \\
022\end{array}$ & $\begin{array}{l}36.1 \\
045\end{array}$ \\
\hline \multirow[t]{2}{*}{$\mathrm{Y}$} & $\begin{array}{l}\text { Lognor } \\
\text { mal }\end{array}$ & $\begin{array}{l}\mu \\
=6.4423087 \\
\sigma \\
=0.3155765\end{array}$ & $\begin{array}{l}406.4 \\
736\end{array}$ & $\begin{array}{l}409.2 \\
76\end{array}$ \\
\hline & Weibull & $\begin{array}{l}\mathrm{k} \\
=3.204578 \\
\lambda \\
=735.4654\end{array}$ & $\begin{array}{l}411.0 \\
684\end{array}$ & $\begin{array}{l}413.8 \\
708\end{array}$ \\
\hline \multirow[t]{2}{*}{$\begin{array}{l}\mathrm{CH} \\
\mathrm{S}\end{array}$} & $\begin{array}{l}\text { Lognor } \\
\text { mal }\end{array}$ & $\begin{array}{l}\mu \\
=6.445887 \\
\sigma \\
=0.4199907\end{array}$ & $\begin{array}{l}423.83 \\
82\end{array}$ & $\begin{array}{l}426.64 \\
06\end{array}$ \\
\hline & Weibull & $\begin{array}{l}\mathrm{k}=2.63981 \\
\lambda \\
=776.18165\end{array}$ & $\begin{array}{l}456.7 \\
343\end{array}$ & $\begin{array}{l}459.5 \\
367\end{array}$ \\
\hline
\end{tabular}

Selanjutnya dengan merujuk pada nilai korelasi Kendall tau, representasi pohon copula untuk variabel harga gabah $(\mathrm{P})$, hasil panen $(\mathrm{Y})$, dan curah hujan $(\mathrm{C})$ data pada Kecamatan Dlingo, Bantul dapat direpresentasikan sebagai berikut

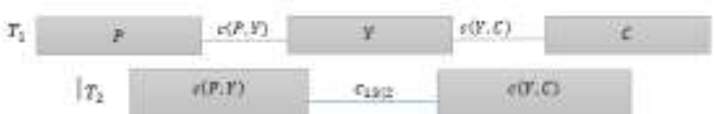

Gambar 1 Sturktur Copula D-Vine berdimensi $(\mathrm{d}=3)$

\section{Transformasi Data ke Bentuk Uniform $[0,1]$}

Dengan mengasumsikan semua variabel berdistribusi Lognormal maka dengan memperhatikan konstruksi data pada distribusi Lognormal ke bentuk Uniform Standard diperoleh $u_{1}=F_{1}(p) \in[0,1]$ dan $u_{2}=$ $F_{2}(y) \in[0,1], \quad$ dan $u_{3}=F_{3}(c) \in[0,1]$ sebagai data awal
Tabel 3. Transformasi Data Distribusi

Lognormal ke Bentuk Uniform $[0,1]$

\begin{tabular}{|c|c|c|c|}
\hline No & $u_{1}$ & $u_{2}$ & $u_{3}$ \\
\hline 1 & 0.834293019 & 0.880213917 & 0.729940982 \\
\hline 2 & 0.971913468 & 0.990426166 & 0.852390954 \\
\hline 3 & 0.949667701 & 0.060600506 & 0.126671984 \\
\hline 4 & 0.475654922 & 0.809708368 & 0.404049596 \\
\hline$\vdots$ & $\vdots$ & $\vdots$ & $\vdots$ \\
\hline 29 & 0.083219203 & 0.455305995 & 0.082819283 \\
\hline 30 & 0.014185934 & 0.449077356 & 0.429812994 \\
\hline
\end{tabular}

3. Pemilihan Copula Terbaik Pada $T_{1}$

Sebelum masuk kedalam penentuan copula terbaik, terlebih dahulu dilakukan uji independent untuk tiap pasangan data dari $u_{1}, u_{2}$, dan $u_{3}$. Berdasarkan nilai hasi uji independenitas pada tabel 3 diperoleh bahwa hipotesis null $\left(H_{0}\right)$ hanya diterima pada pasangan data $\left(u_{1}, u_{3}\right) p$-value $0.06425701>$ 0.05 . Artinya bahwa $u_{1}$ dan $u_{3}$ independen.

\section{Tabel 4. Uji Independenitas Bivariat}

\begin{tabular}{|c|c|c|c|}
\hline $\begin{array}{c}\text { Hasi } \\
\text { Uji }\end{array}$ & $\left(u_{1}, u_{2}\right)$ & $\left(u_{2}, u_{3}\right)$ & $\left(u_{1}, u_{3}\right)$ \\
\hline p-value & 0.0171329 & 0.000825889 & 0.0642570 \\
& 3 & 8 & 1 \\
\hline $\begin{array}{c}\text { Statisti } \\
\text { c }\end{array}$ & 2.383843 & 3.343969 & 1.850392 \\
\hline
\end{tabular}

Uji Hipotesis Independen Test (Genest \& Favre, 2007):

Ho: $C=\prod$ dari independen antara X dan $\mathrm{Y}$ $H_{1}: C \neq \prod$ dari independen antara $\mathrm{X}$ dan $\mathrm{Y}$

Berdasarkan nilai BIC dari hasil perhitungan pada edge $c_{1,2}\left(u_{1}, u_{2}\right)$ dan edge $c_{2,3}\left(u_{2}, u_{3}\right)$, untuk edge $c_{1,2}\left(u_{1}, u_{2}\right)$ dependensi terbaik untuk variabel harga gabah dan luas hasil panen adalah copula Joe dengan parameter $\theta=1.76$, korelasi $\rho_{\tau}=0.3$ dan upper tail dependensi $=0.52$. Sedangkan untuk dependensi pada $c_{2,3}\left(u_{2}, u_{3}\right)$ copula terbaik yang mampu memberikan gambaran depedensi terbaik antara indek standar curah hujan dan hasil panen adalah copula Frank dengan parameter $\theta=4.98$ dan korelasi $\rho_{\tau}=0.46$.

\section{Pemilihan Copula Terbaik Pada $T_{2}$}

Untuk menentukan copula terbaik yang dapat menggambarkan dependensi pada edge $c_{1,3 \mid 2}$ pada $T_{2}$, maka terlebih dahulu dibentuk nilai dari $F_{1 \mid 2}\left(u_{1} \mid u_{2}\right)$ dan $F_{3 \mid 2}\left(u_{3} \mid u_{2}\right)$. Hasil perhitungan pada $c_{1,3 \mid 2}$ mengindikasikan bahwa terdapat error pada pada perhitungan dependensi antara variabel $u_{1}$ dan $u_{3}$ terhadap $u_{2}$. Asumsi ini didukung dengan hasil uji independent test pada $\left(F_{1 \mid 2}\left(u_{1} \mid u_{2}\right)\right.$ dan $F_{3 \mid 2}\left(u_{3} \mid u_{2}\right)$, dengan $p-$ value $=0.4644846>0.05$. Merujuk pada 
hasil uji indepdent test untuk $F_{1 \mid 2}\left(u_{1} \mid u_{2}\right)$ dan $F_{3 \mid 2}\left(u_{3} \mid u_{2}\right)$ maka uji hipotesis $H_{0}$ diterima. Sehingga diasumsikan $c_{1,3 \mid 2}$ independent, atau

$$
c_{1,3 \mid 2}\left(F_{1 \mid 2}\left(u_{1} \mid u_{2}\right), F_{3 \mid 2}\left(u_{3} \mid u_{2}\right) ; \theta_{1,3 \mid 2}\right)=1 \text {. }
$$

\section{Pembentukan Simulasi Data}

Untuk melakukan perhitungan tetapan hasil panen dan harga gabah dan indek standar curah hujan peneliti melakukan data simulasi sebanyak 1000 berdasarkan parameter dari copula terbaik. Hasil data simulasi kemudian diubah kedalam bentuk distribusi pada data empiriknya. Dengan memanfaatkan transformasi data dengan memperhatikan nilai mean dan variansi dari distribusi Lognormal dari setiap variabel random diperoleh nilai pasangan $(P, Y)$ dan $(Y, C)$.

Tabel 5. Data Berdasarkan Pasangan Bivariat Copula

\begin{tabular}{|c|c|c|c|c|}
\hline \multirow{2}{*}{ No } & \multicolumn{2}{|c|}{$(P, Y)$} & \multicolumn{2}{c|}{$(Y, C)$} \\
\cline { 2 - 5 } & $P$ & $Y$ & $Y$ & $C H S$ \\
\hline 1 & 3419 & 502 & 715 & 764 \\
\hline 2 & 3470 & 425 & 319 & 670 \\
\hline 3 & 3576 & 861 & 846 & 1039 \\
\hline 4 & 3820 & 834 & 559 & 507 \\
\hline$\vdots$ & $\vdots$ & $\vdots$ & $\vdots$ & $\vdots$ \\
\hline 999 & 3578 & 536 & 461 & 579 \\
\hline 1000 & 4129 & 907 & 481 & 888 \\
\hline
\end{tabular}

Untuk membentuk sampel data dimana $P$ masih terikat dengan dengan pasangan $(Y, C)$, peneliti membangun data berdasarkan tabel 5 dengan memanfaatkan algortima pembentukan data sampel dengan membentuk $W_{3}=U_{3}, W_{2}=$ $U_{2}$, dan $W_{1}=F_{1 \mid 2}^{-1}\left(U_{1} \mid W_{2}\right)$. Sehingga dengan mengambil data $U_{2}, U_{3}$ dari pasangan $\left(U_{2}, U_{3}\right)$ dan $U_{1}$ dari pasangan $\left(U_{1}, U_{2}\right)$ pada vine copula diperoleh data $P, Y, C$ sebagai berikut.

Tabel 6 Simulasi Data Berdasarkan Algoritma

\begin{tabular}{|c|c|c|c|}
\multicolumn{2}{|c|}{ Sampel pada Copula Vine } \\
\hline No & $P$ & $Y$ & $C$ \\
\hline 1 & 3457 & 715 & 764 \\
\hline 2 & 3358 & 777 & 554 \\
\hline 3 & 3732 & 749 & 395 \\
\hline 4 & 3696 & 830 & 913 \\
\hline$\vdots$ & & $\vdots$ & $\vdots$ \\
\hline 999 & 3467 & 828 & 1495 \\
\hline 1000 & 4068 & 717 & 467 \\
\hline Rata-Rata & 3591 & 656 & 692 \\
\hline
\end{tabular}

Untuk memberikan komparasi perbandingan nilai untuk $P, Y$ dan $C$ dari hasil pembentukan data simulasi dari copula Vine, peneliti menggunakan konsep multivariat copula Gaussian sebagai pembanding. Berdasarkan nilai $v_{1}, v_{2}$, dan $v_{3}$ pada tabel 3 diperoleh nilai $C_{G}\left(v_{1}, v_{2}, v_{3}\right)$ sebagai berikut.

Tabel 7 Nilai $C_{G}\left(v_{1}, v_{2}, v_{3}\right)$ untuk Standar Multivariat Copula Gaussian

\begin{tabular}{|c|c|c|c|c|}
\hline No & $v_{1}$ & $v_{2}$ & $v_{3}$ & $C_{G}\left(v_{1}, v_{2}, 2\right.$ \\
& & & & $\cdot$ \\
\hline 1 & 0.6745 & 0.87972 & 0.674 & 0.589828 \\
& 70 & 07 & 5 & 26 \\
\hline 2 & 0.8482 & 0.99894 & 0.848 & 0.840105 \\
& 69 & 50 & 2 & 02 \\
\hline 3 & 0.1467 & 0.09847 & 0.146 & 0.043740 \\
& 45 & 43 & 7 & 39 \\
\hline 4 & 0.3381 & 0.78487 & 0.338 & 0.227633 \\
& 78 & 27 & 1 & 29 \\
\hline$\vdots$ & $\vdots$ & $\vdots$ & $\vdots$ & $\vdots$ \\
\hline 29 & 0.1180 & 0.40008 & 0.118 & 0.030971 \\
& 31 & 95 & 0 & 70 \\
\hline 30 & 0.3591 & 0.39465 & 0.359 & 0.015324 \\
& 04 & 96 & 1 & 14 \\
\hline
\end{tabular}

Berdasarkan nilai matriks korelasi dari $C_{G}\left(v_{1}, v_{2}, v_{3}\right)$, selanjutnya dibentuk sebanyak 1000 data simulasi. Bila dibandingkan antara rataan data pada tabel 4.15 dan tabel 4.16 maka terdapat sedilit perbedaan diantara nilai rataan dari data pembentukan berdasarkan konsep copula Vine dan standar mutivariat copula Gaussian.

Tabel 8 Data Simulasi Berdasarkan Standar Multivariat Copula Gaussian

\begin{tabular}{|c|c|c|c|}
\hline No & $P_{G}$ & $Y_{G}$ & $C_{G}$ \\
\hline 1 & 3423 & 760 & 672 \\
\hline 2 & 3801 & 694 & 763 \\
\hline 3 & 3777 & 785 & 784 \\
\hline$\vdots$ & $\vdots$ & $\vdots$ & $\vdots$ \\
\hline 999 & 3760 & 627 & 365 \\
\hline 1000 & 3275 & 399 & 500 \\
\hline Rata-Rata & 3599 & 652 & 691 \\
\hline
\end{tabular}

Berdasarkan kedua table diatas dapat dilihat bahwa hasil output untuk ketiga variable dengan menggunakan Multivariat copula dalam hal ini multivariat copula dan Copula Gaussian menghasilkan rata-rata hasil yang cukup identik. Sehingga hasil ini dapat dijadikan sebagai acuan dalam menentukan hasil perhitungan premi selanjutnya.

\section{KESIMPULAN dan SARAN}

Dalam menganalisa depedensi variablevariabel yang dapat digunakan dalam perhitunagn asuransi pertanian, dapat dilihat bahwa baik menggunakan multivariate copula dan vine copula memiliki hasil yang sama. 
Copula multivariate yang secara langsung melihat hubungan depedensi antara tiga variable. Sedangkan copula vine dapat melihat nilai-nilai ukuran depedensi anatar pasangan variable untuk setiap edge pada pohon copula vine. Secara lebih mendetail dependensi terbaik untuk variabel harga gabah dan curah hujan adalah Copula Joe dengan parameter $\theta=1.76$. korelasi $\tau=0.3$. Dependensi terbaik antara curah hujan dan hasil panen adalah Copula Frank dengan parameter $\theta=4.98$ dan korelasi $\tau=0.46$. Dependensi terbaik antara curah hujan dan hasil panen adalah copula Frank dengan parameter $\theta=2.42$ dan korelasi $\tau=0.25$.

\section{UCAPAN TERIMA KASIH}

Pada kesempatan ini, penulis mengucapkan terima kasih yang sebesar - besarnya kepada Universitas Terbuka telah memberi dukungan finansial terhadap penelitian ini, sehingga penulis dapat menyelesaiakan penelitian ini dengan baik dan tepat waktu.

\section{DAFTAR PUSTAKA}

[1] Vaulina, S., \& Rahmi, E. (2004). Peran Sektor Pertanian dalam Perekonomian Kabupaten Indragiri Hilir Propinsi Riau. Dinamika Pertanian, 28(3)

[2] Nasional Kontan.(Online). (2019). Hingga awal Juli, realisasi Asuransi Usaha Tani Padi (AUTP) baru capai 232.255 hektar. diaskes melalui halaman https://nasional.kontan.co.id/news/hin gga-awal-juli-realisasi-asuransi-usahatani-padi-autp-baru-capai-232255hektar

[3] Adeyinka, A. A., Krishnamurti, C., Maraseni, T. N., \& Chantarat, S. (2016). The viability of weather-index insurance in managing drought risk in rural Australia. International Journal of Rural Management, 12(2), 125-142.

[4] Zhu, J.S., 2011. Evaluation of an Insurance Scheme Based on the Weather Index: A Case Study of Anhui Province. Chinese Economy, 44(6), pp.56-72.

[5] Ren, X., Li, S., Lv, C. dan Zhang, Z., 2014. Sequential dependence modeling using Bayesian theory and D-vine opula and its application on chemical process risk prediction. Industrial \& Engineering Chemistry Research, 53(38), pp.14788-14801.

[6] Lin, J., Boyd, M., Pai, J., Porth, L., Zhang, Q., \& Wang, K. (2015). Factors affecting farmers' willingness to purchase weather index insurance in the Hainan Province of China. Agricultural Finance Review, 75(1), 103-113.

[7] Pishbahar, E., Abedi, S., Dashti, G. dan Kianirad, A., 2016. Measuring the Dependency Structure between yield and Weather Variabels for Ratemaking Weather-Based Crop Insurance in Ahar. European Online Journal of Natural and Social Sciences, 5(2), p.421.

[8] Bokusheva, R. (2011). Measuring dependence in joint distributions of yield and weather variables. Agricultural Finance Review, 71(1), 120-141.

[9] Breustedt, G., Bokusheva, R., \& Heidelbach, O. (2008). Evaluating the potential of index insurance schemes to reduce crop yield risk in an arid region. Journal of Agricultural Economics, 59(2), 312-328.

[10] Bokusheva, R. (2018). Using copulas for rating weather index insurance contracts. Journal of Applied Statistics, 45(13), 2328-2356.

[11] Aas, K., \& Berg, D. (2010). Modeling dependence between financial returns using pair-copula constructions. In Dependence modeling: Vine copula handbook (pp. 305-328).

[12] Mai, J., Scherer, Matthias, \& World Scientific. (2012). Simulating copulas : Stochastic models, sampling algorithms and applications (Series in quantitative finance; v. 4)

[13] Aas, K., Czado, C., Frigessi, A., \& Bakken, H. (2009). Pair-copula constructions of multiple dependence. Insurance: Mathematics and economics, 44(2), 182-198 